\title{
Humor político en el live tweeting. Sus clases y circulaciones en la construcción de acontecimientos
}

\author{
Political humor in live tweeting. Its kinds and circulations in the \\ construction of events
}

Fraticelli, Damián

Universidad de Buenos Aires (UBA) y Universidad Nacional de las Artes (UNA) fraticelli@sociales.uba.ar

Forma de citar este artículo:

Fraticelli, D. (2022). Humor político en el live tweeting. Sus clases y circulaciones en la construcción de acontecimientos. RAE-IC, Revista de la Asociación Española de Investigación de la Comunicación, 9(17), 1-24.

https://doi.org/10.24137/raeic.9.17.1

\section{Resumen:}

El tuiteo de humor político sobre transmisiones televisivas es una práctica habitual que debe atenderse si quiere comprenderse cómo se construyen los acontecimientos en las sociedades actuales. Su existencia implica complejos procedimientos de apropiación colaborativa por parte de los internautas y también de los medios informativos que editorializan los eventos con sus memes. Aquí nos ocuparemos de describir de qué manera opera ese humor político enfocándonos en cómo actúan sus enunciadores, qué clases discursivas y tipos de circulaciones genera. Los eventos analizados son el primer discurso de apertura de las sesiones legislativas del presidente argentino Alberto Fernández, en marzo del 2020, y el debate en el Senado argentino de la Ley de Interrupción Voluntaria del Embarazo, en diciembre del mismo año. Su análisis nos posibilitó observar que el humor político del live tweeting tiene más retuiteos y likes que 
los tuits serios y que sus intercambios no se agotan en lo risible, sino que fomentan debates entre los internautas. A su vez, distinguimos cuatro clases discursivas (la sátira política, la burla, la situación cómica y el humor del colectivo) que implican modos diferentes de contactarse con el evento transmitido y circunscribimos modalidades de apropiación de las instituciones informativas.

Palabras clave: Humor político, Live tweeting, Twitter, Política.

\section{Abstract:}

The tweeting of political humor on television broadcasts is a common practice that should be considered if we want to understand how events are constructed in today's societies. Its existence implies complex procedures of collaborative appropriation by Internet users and by the media that editorialize the events with their memes. Here we will describe how this political humor operates, focusing on how its enunciators act, what kinds of discourse it produces and the types of circulations it generates. The events analyzed are the first speech at the opening of the legislative sessions of Argentine President Alberto Fernández, in March 2020, and the debate in the Argentine Senate on the Law on the Voluntary Interruption of Pregnancy, in December of the same year. Its analysis allowed us to observe that the political humor of live tweeting has more retweets and likes than serious tweets and that its exchanges are not limited to the laughable but encourage debates among Internet users. In turn, we distinguished four discursive classes (political satire, mockery, the comic situation, and collective humor) that imply different ways of contacting the transmitted event and we circumscribe modalities of appropriation of the informative institutions.

Keywords: Political Humor, Live tweeting, Twitter, Politics.

\section{INTRODUCCIÓN}

Una práctica de espectación televisiva se instaló con la aparición de Twitter: el humor político del live tweeting o del tuiteo sobre eventos transmitidos en directo. Esta apropiación colaborativa del discurso televisivo no puede ignorarse, si quiere comprenderse cómo se construyen los acontecimientos en las sociedades 
contemporáneas (Jenkins, Ford y Green, 2015; Scolari, 2013). Aquí describiremos cómo opera, cuáles son sus clases discursivas y circulaciones hipermediáticas ${ }^{1}$.

En la modernidad y posmodernidad, los medios de comunicación masiva dominaban la fabricación de la realidad como experiencia socialmente compartida (Verón 1987a). En la contemporaneidad, en cambio, ella se produce en los constantes intercambios que se dan entre aquellos y los medios con base en Internet y la telefonía (Carlón, 2015, 2020). El humor político del live tweeting se da en esa interacción apropiándose de esas imágenes y sonidos televisivos, generando interpretantes que enmarcan ${ }^{2}$ el acontecer social en lo reidero 3 . Por "interpretantes" nos referimos al concepto de Peirce (1974) quien lo entiende como signos suscitados en la relación de un representamen con un objeto según algún fundamento; o, en términos de Verón (1987b, 2013), aludimos a que ciertos discursos surgen en la vinculación de ciertas condiciones productivas con ciertos objetos. Los interpretantes risibles (memes, gifs cómicos, tuits burlones, etc.) construyen el acontecimiento con una lógica diferente a la que domina lo serio. En ellos están habilitadas incongruencias, ridiculizaciones y ofensas que serían inadmisibles si no se desarrollaran en su marco metacomunicacional (Fraticelli, 2019).

La participación del humor político en la construcción de acontecimientos no es una novedad, tempranamente se articuló con los medios de comunicación masiva y el periodismo. No obstante, existen significativas diferencias entre el humor político de los medios masivos y el hipermediático. Tres de ellas nos interesan particularmente por ser condición de posibilidad de nuestro objeto de estudio: su producción mayoritariamente está hecha por amateurs, tiene baja regulación institucional ${ }^{4}$ y puede darse de manera simultánea a los acontecimientos que referencia. Nuestro escrito se enfocará especialmente en este último aspecto intentando hacer algunos aportes a las

\footnotetext{
1 Por "circulación comprendemos el desfase entre la instancia de producción y reconocimiento de los discursos (Verón 1987). Carlón $(2015,2020)$ se apropia de la noción sumándole el adjetivo "hipermediática" para describir la producción del sentido que se dan en las sociedades el sistema de medios masivos interactúa con el de las redes sociales.

2 El término "enmarcar" hace referencia a los procedimientos metacomunicacionales teorizados por Bateson (1985 [1972]) y Goffman (2006 [1975]). En Fraticelli (2019) desarrollamos lo reidero como un marco metacomunicacional.

3 Con "reidero" y "risible" definiremos al dominio semiótico que contiene géneros, tipos y procedimientos discursivos que promueven la risa (Traversa, 2009). El término "humor" lo utilizaremos para indicar un modo particular de generar lo risible: el que implica una enunciación reflexiva que incluye al enunciador y enunciatario en el blanco de la burla.

${ }^{4}$ No sostenemos que no exista regulación institucional en las plataformas mediáticas, sino que ella es incomparable a la existente en los medios de comunicación masiva. En las plataformas no existe algo similar a un manual de estilo y la censura se ejerce luego de haberse dado la emisión. Además, lo que es censurado en una plataforma puede no serlo en otra y los internautas suelen sortear sus censores automáticos. En Fraticelli (2018) analizamos el tema con respecto al cyberbullying.
} 
investigaciones realizadas. Para ello, primero, revisaremos la bibliográfica para sintetizar los acuerdos que existen sobre el objeto y cuáles son los límites de su abordaje. Luego, expondremos la metodología que utilizamos en nuestros estudios $y$, finalmente, analizaremos las clases y circulaciones del humor político del live tweeting tomando dos eventos: el discurso de apertura de las sesiones legislativas del presidente argentino Alberto Fernández, en marzo del 2020, y el debate de la Ley de Interrupción Voluntaria del Embarazo que, en diciembre de ese año, se dio en el Senado argentino que terminó aprobándola. Sobre el primer caso retomaremos los resultados obtenidos en un análisis anterior que aquí se amplían y corrigen (Fraticelli, Gómez Blanco, Saldaña y Taraborrelli, 2020).

Somos conscientes que ambos acontecimientos, aunque políticos, son de diferente naturaleza, pero esa elección es adrede porque lo que nos interesa es aprehender qué regularidades presenta el humor político en el live tweeting aún en casos disímiles. Así, indagaremos cómo actuaron los enunciadores reideros antes, durante y después de cada evento, cuáles fueron las clases discursivas de sus producciones y cómo fue su circulación al ser apropiadas por portales de noticias y de medios masivos.

\section{EL ESTUDIO DEL HUMOR POLÍTICO EN EL LIVE TWEETING: CONTRIBUCIONES Y}

\section{LÍMITES}

En la bibliografía consultada predomina el análisis cuantitativo antes que el cualitativo y se utilizan programas de procesamiento de big data con el objetivo de encontrar regularidades en el humor político del live tweeting sobre un evento en particular, especialmente debates entre candidatos políticos y elecciones (Davis, Love y Killen, 2018; Driscoll, Leavitt, Kristen, François, Aalot, 2013; Freelom y Karpf 2014; Highfield 2015; Maradei, 2017; Wells et al 2016). Entre las conclusiones compartidas se encuentra que los tuits reideros alcanzan más retuiteos que los serios y que esto supone una mayor capacidad para instalar temas en el debate político y marcos interpretativos de larga duración. A su vez, los momentos risibles de los eventos (accidentes cómicos, fursios, chanzas, etc.) aumentan los retuiteos fomentando un tono jocoso a la discusión política. Esto no significa que lo reidero genere un desprecio por lo político sino lo contrario. Los estudios coinciden en señalar que los tuits y retuiteos risibles provocan intercambios 
serios que avivan la discusión política y que suma a ella a los ciudadanos que no son convocados por los discursos serios.

Estas conclusiones, interesantes para ser contrastadas en diferentes países, significan un progreso en el conocimiento de cómo opera el humor político de Twitter en la construcción de acontecimientos en directo. Sin embargo, se ven limitadas por la desatención a dos cuestiones que sería conveniente incorporar para seguir avanzando: el estudio de la enunciación de los discursos risibles y de la circulación hipermediática.

Usualmente, los análisis cualitativos de las investigaciones se refieren a lo risible con el término "humor" definiéndolo de manera amplia sin discriminar la inmensa variedad en la que se genera lo risible (chiste, chanza, parodia, etc.). Y solo se ocupan de establecer si es a favor o en contra del político referenciado y qué temas alude. Lo que predomina es un análisis de contenido que ignora la enunciación. Esto no es una cuestión menor porque lo enunciativo define lo risible en varios sentidos. El mismo meme puede ser cómico o humorístico ${ }^{5}$ según quien enuncia. Las diferentes clases de lo risible implican diferentes modos de convocar a los internautas y conformar colectivos. Y, además, a través de lo enunciativo tendremos hipótesis sobre cómo generan placer risible los tuits, algo fundamental si se quiere explicar por qué algunos son más compartidos que otros, porque si no son graciosos, pocas posibilidades tienen de propagarse.

Con respecto a la circulación hipermediática, las investigaciones toman un único tipo de dirección comunicacional, la descendente: de los medios masivos (la televisión) hacia las redes mediáticas (Twitter). No analizan la otra dirección comunicacional de eventos importantes, la ascendente: de las redes hacia los medios masivos. Esa desatención hace que no se aborden aspectos relevantes del humor político del live tweeting como las inflexiones del sentido que toma el acontecimiento construido por las cuentas originales o los incrementos de visionados y retuiteos que adquieren los tuits apropiados.

\footnotetext{
${ }^{5}$ Es abundante la bibliografía dedicada a la distinción entre lo cómico y el humor. Por cuestiones de espacio, no la expondremos. Nosotros comprendemos a ambos como dos grandes regímenes enunciativos que se distinguen por el vínculo que proponen con el objeto risible. Lo cómico implica una relación asimétrica superior con respecto al objeto y de distanciamiento en el que no hay espacio para la identificación. El humor, en cambio, propone una relación de identificación que hace que el propio enunciador y enunciatario sean parte del objeto reidero. Si lo cómico es reírse de otro, el humor es reírse con el otro de uno mismo.
} 
Por estas razones, nuestro estudio prestará atención a las distintas clases discursivas del humor político del live tweeting, con sus respectivas enunciaciones, y a sus circulaciones hipermediáticas, esperando hacer un aporte al conocimiento producido hasta el momento.

\section{ALGUNAS DEFINICIONES SOBRE EL CORPUS DE ANÁLISIS Y LA METODOLOGÍA}

Como planteamos en la introducción, los dos acontecimientos seleccionados para el análisis fueron: el discurso del presidente argentino Alberto Fernández inaugurando las sesiones legislativas en el Congreso de la Nación el 1 de marzo de $2020^{6}$ y el debate en el Senado de la Ley de interrupción voluntaria del embarazo que comenzó el 29 diciembre del mismo año y terminó a las 4:12 am del día siguiente aprobándose la ley . En ambos casos, el período estudiado fue desde las 9 a.m. del día que ocurrió el evento hasta las 12 p.m. del día siguiente. El corpus de análisis lo conformamos con los tuits risibles de los hashtags principales de Twitter $^{8}$ y los publicados por cuentas de enunciadores reideros con un máximo de 200 mil seguidores ( 25 cuentas para el discurso y 20, para el debate). ${ }^{9}$ También se incorporaron las noticias dedicadas a los tuits risibles sobre ambos eventos publicadas por portales de noticias y de medios masivos.

Sobre este corpus se realizó un análisis cuantitativo usando el RStudio que nos permitió extraer los datos de Twitter. En el análisis cualitativo utilizamos el modelo de la teoría de los discursos sociales de Verón $(1987,2013)$, el de la circulación hipermediática de Carlón (2020) y el de los niveles enunciativos de las interfaces de las redes mediáticas (Fraticelli, 2021) ${ }^{10}$. Este último nos posibilitó atender al problema que mencionábamos

\footnotetext{
${ }^{6}$ El primer caso de COVID-19 en Argentina fue el 3 de marzo del 2020. El 20 del mismo mes se decretaba la primera cuarentena con 700 enfermos. En el momento en que Alberto Fernández daba su discurso la pandemia aún no ocupaba un lugar central en la agenda de los medios masivos.

${ }^{7}$ El proyecto de ley había sido aprobado por la Cámara de Diputados el 11 de diciembre, solo faltaba la afirmación del Senado para ser ley.

${ }^{8}$ Los hashtags del discurso del presidente Fernández fueron: \#AbortoLegal2020, \#TodosConAlberto, \#AsambleaLegislativa2020, \#MacriEsEducación, \#NoSeBancaMás, \#16MParoCiudadano, \#HeladerasVacías. Los hashtags del debate en el Senado fueron: \#AbortoLegal, \#AbortoLegalSeguroYGratuito, \#AbortoLegalYa, \#AbortoLegal2020, \#ArgentinaEsProvida, \#Provida, \#ArgentinaSinAborto, \#ArgentinaEsCeleste.

9 Las cuentas del discurso del presidente Fernández fueron: Sigi Karl, Dr Víctor Tutú, Malcom Gómez, Ann, vicosu2019, Conciencia2015, dsgny, Juan Carlos, Yo voto por Carrió, Ana Alvez, Ángeles Morena, DaniVillegas, TAP, Gonzalo Lozano, Steve zonajobs, So payaso, Chirusita Power, Vito, Revista Barcelona, Lucas, El Editor, Lucas Baini, Martha, Salieri de Nik, Tomás Sánchez. Las cuentas del debate en el Sentado fueron: Deadflix, Revista Barcelona, El Editor, EAmeo, Argensimpsons, Martha M. Lamartha, Lucas Baini, Coronel Gorronea, Lucas, Vito, Dr. Victor Tutú, El Cipayo Argentino, Mariano Orwell, Malcom Gómez, Winston, Nelson Mutz, Salieri de Nik, Lu Palavecino, Basta!, Chetoscolovaquia.

10 Una exposición de este modelo puede verse a partir de las 2 horas y 28 minutos en: https://www. youtube. com/watch?v=fRVTWQnmHdc
} 
arriba: un mismo meme cambia su carácter risible según su enunciación. Por ello, no solo analizamos los tuits recolectados, sino que además observamos las publicaciones anteriores de las cuentas para saber qué identidades políticas venían construyendo. A su vez, también atendimos a los intercambios previos y posteriores al tuit analizado para identificar ironías o desviaciones a las expectativas construidas por esas identidades.

\section{LA CONSTRUCCIÓN DEL ACONTECIMIENTO POR EL HUMOR POLÍTICO DEL LIVE TWEETING}

Hecha la revisión bibliográfica y expuesta la metodología, abordaremos ahora cómo operó el humor político del live tweeting en la construcción de los eventos nombrados. Primero, expondremos algunas tendencias cuantitativas generales, luego distinguiremos cómo actuó lo risible en la polarización, cuáles fueron sus clases discursivas dominantes y cómo las instituciones informativas se las apropiaron.

\subsection{ALGUNAS OBSERVACIONES GENERALES}

En los hashtags escogidos recolectamos 94131 tuits sobre discurso de Fernández y 123457 sobre del debate del Senado. En ellos distinguimos 17 tuits risibles, en el primero, y 45 , en el segundo, es decir, solo un $0,01 \%$ y un $0,03 \%$ del total de tuits publicados en los hashtags fueron reideros. Esto es una cantidad ínfima, sin embargo, tuvieron un promedio mucho más alto que lo serios en cantidad de retuits y likes. En el discurso, los tuits risibles alcanzaron un promedio de 71,4 retuits y 118 likes, mientras que los serios solo 11 retuits y 76 likes. Y, en el debate, los risibles tuvieron un promedio de 178,8 retuits y 1637 likes, y los serios 28 retuits y 97 likes. Este resultado confirmaría la conclusión de las investigaciones citadas de que lo reidero es más compartido que lo serio.

Esta inclinación es mayor si observamos los tuits reideros recogidos de las cuentas antes presentadas. Las del discurso del presidente tuvieron un promedio de 792,5 likes y 470,3 retuits y, las del debate en el Senado, alcanzaron un promedio de 968,4 likes y 530,2 retuits. 
A su vez, hubo una significativa producción reidera dispersa en Twitter en ambos eventos. En el discurso de Fernández, fue tendencia "Alberto Portter"11, una condensación cómica entre el nombre del presidente (Alberto) y el apellido del protagonista de Harry Portter sostenida en el parecido de sus anteojos. Y, en el debate del Senado, fue tendencia "la Petisa", el sobrenombre de la madre de un manifestante opositor a la aprobación de la ley que, en un móvil televisivo, contó que ella, a la que llamó la Petisa, le confesó que hubiera abortado a tres de sus hermanos. La anécdota fue tomada por tantos memes que la posicionó en trending topic.

\subsection{LO REIDERO POLARIZADO}

Para analizar lo reidero según el posicionamiento político distinguimos, en el discurso de Fernández, oficialistas y antioficialistas, y, en el debate del Senado, proley, neutrales, antiley y antipúblico. ${ }^{12}$ Las últimas dos posiciones se manifestaron contra la aprobación de la ley, pero, mientras la primera argumentaba con principios religiosos, humanitarios y jurídicos, la segunda manifestaba como único reparo que el aborto fuera gratuito, porque se pagaría con sus impuestos.

Gráfico 1. Distribución temporal de lo reidero en el discurso del presidente Fernández.

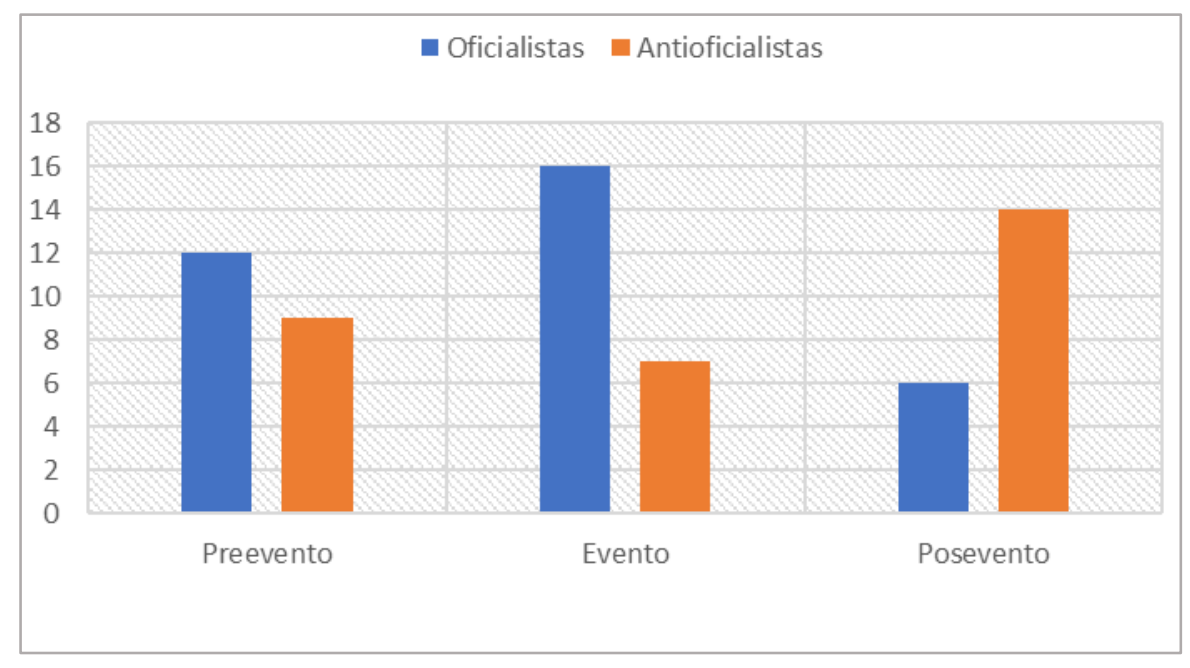

Fuente: Elaboración propia.

\footnotetext{
11 https://www.perfil.com/noticias/politica/discurso-alberto-fernandez-amplio-respaldo-twitter.phtml

12 En Argentina, los que apoyaron la ley se identificaron con pañuelos verdes y quienes se opusieron, con pañuelos celestes. Mediante un proceso metonímico, esos colores representaron ambas posiciones en los medios de comunicación masiva y las redes sociales mediáticas. Aquí utilizamos proley y antiley para sintetizar ambas posiciones y facilitar la lectura a quienes no está habituados a identificarlas con esos colores.
} 
Los memes y tuits risibles de ambos eventos coincidieron en que aparecieron antes, durante y después de la su transmisión televisiva. Pero su distribución política no fue equivalente. El gráfico de abajo muestra que, en el discurso de Fernández, lo reidero oficialista tuvo más presencia antes y durante el evento (gráfico 1). El momento posterior, en cambio, fue el antioficialismo el que generó más tuiteos reideros, lo que implicó que avanzó sobre el oficialismo en la evaluación y síntesis del suceso.

En el debate del Senado, hubo una gran diferencia en el comportamiento de los enunciadores. Los que apoyaron la ley llegaron a publicar 17 veces más tuits risibles que los neutrales y los opuestos a la ley, y esa producción se concentró en el transcurso del evento, aunque también dominó antes y luego de él (gráfico 2).

Gráfico 2. Distribución temporal de lo reidero en el debate del Senado.

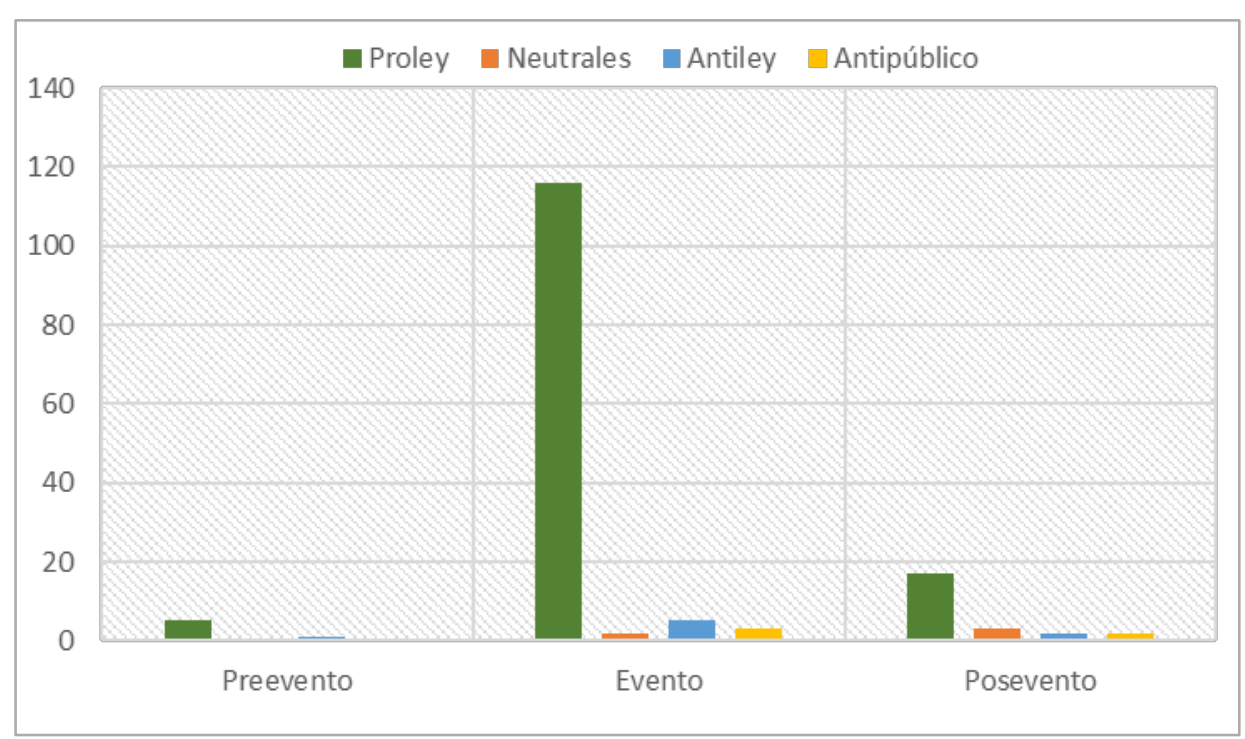

Fuente: Elaboración propia.

En cuanto a la circulación, los gráficos 3 y 4 muestran que, en ambos eventos, la mayor parte de los tuits reideros no tuvieron hashtags, es decir, no se incorporaron al "hilo" que forma Twitter con ellos. Sus destinatarios fueron los integrantes del propio colectivo más que los ajenos. 
Gráfico 3. Distribución de tuits reideros con y sin hashtags del discurso de Fernández.

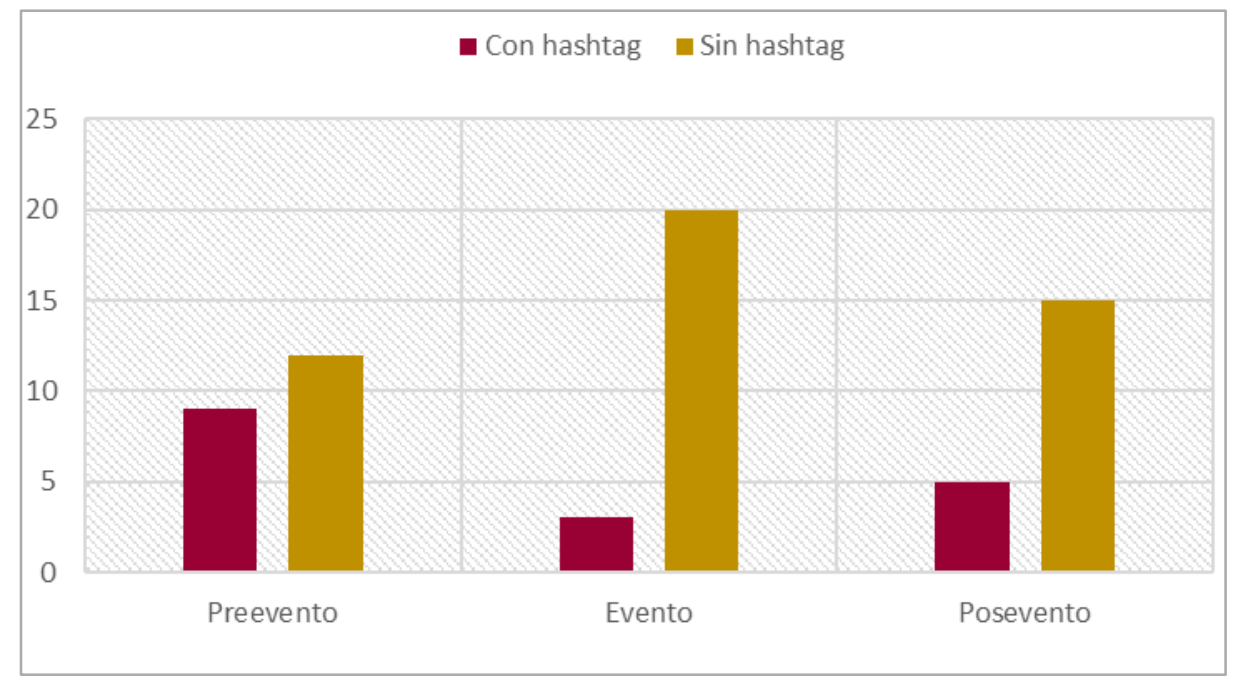

Fuente: Elaboración propia.

Gráfico 4. Distribución de tuits reideros con y sin hashtags del debate del Senado.

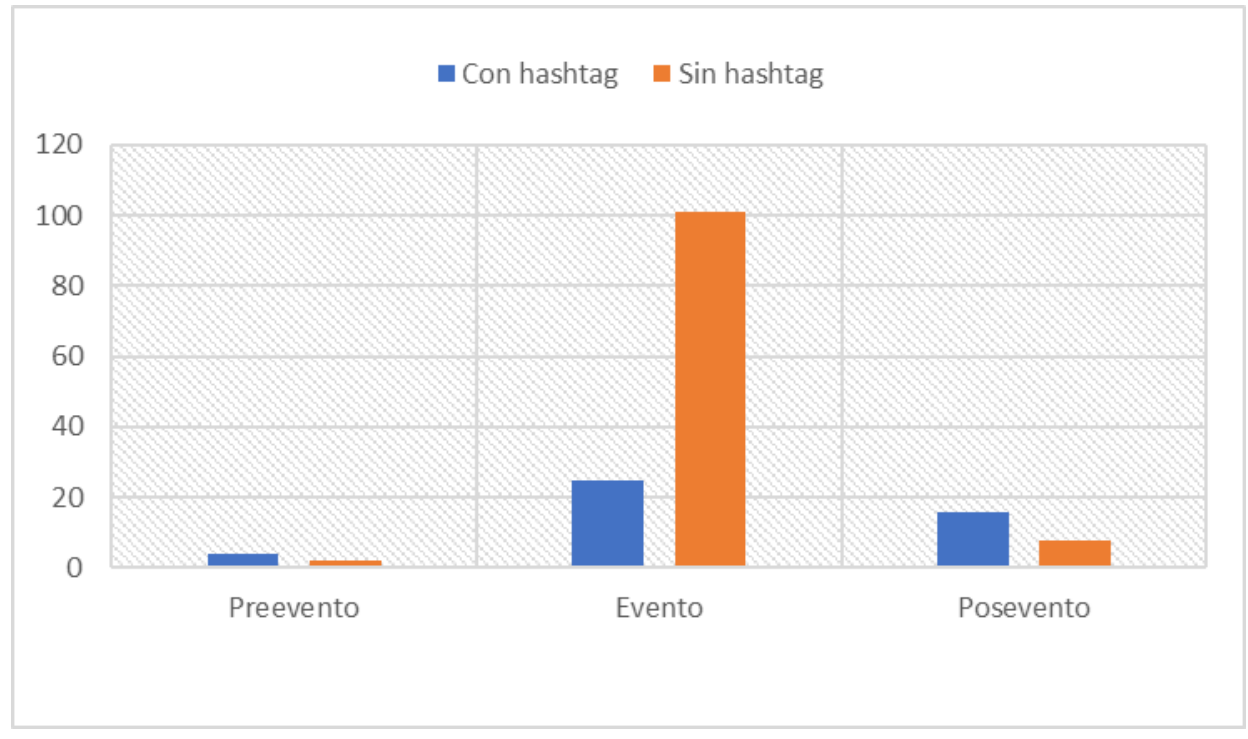

Fuente: Elaboración propia.

Ahora bien, a pesar de esa tendencia general, cuando discriminamos las posiciones políticas de los enunciadores, encontramos tácticas de intercambio diferentes. El gráfico 5 muestra que, en el discurso del Fernández, el antioficialismo buscó el intercambio con otros mientras que el oficialismo se dirigió más a los propios. 
Gráfico 5. Distribución de tuits reideros con hashtags oficialistas y antioficialistas.

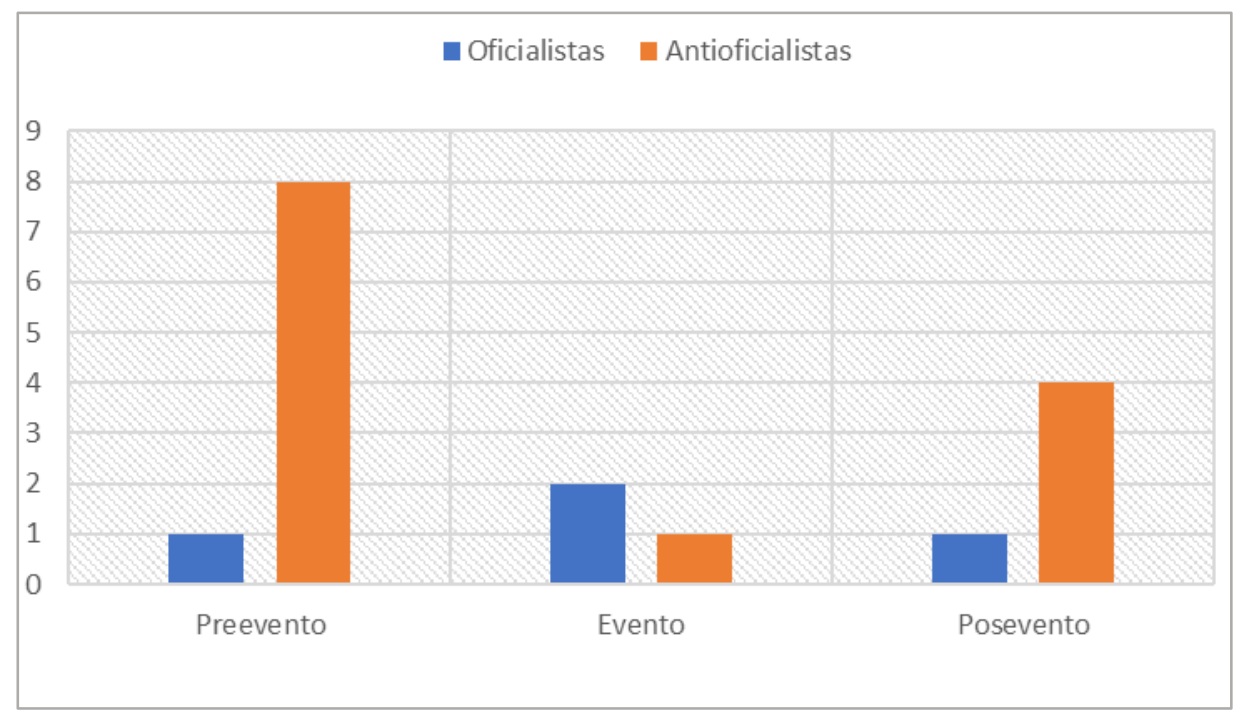

Fuente: Elaboración propia

En el caso del debate en el Senado, el gráfico 6 exhibe que mientras los proley y los antiley publicaron en los hashtags, los neutrales y los antipúblico se dirigieron por completo a sus colectivos de seguidores.

Gráfico 6. Distribución de tuits reideros en hashtags a favor de la ley IVE y contra la ley IVE

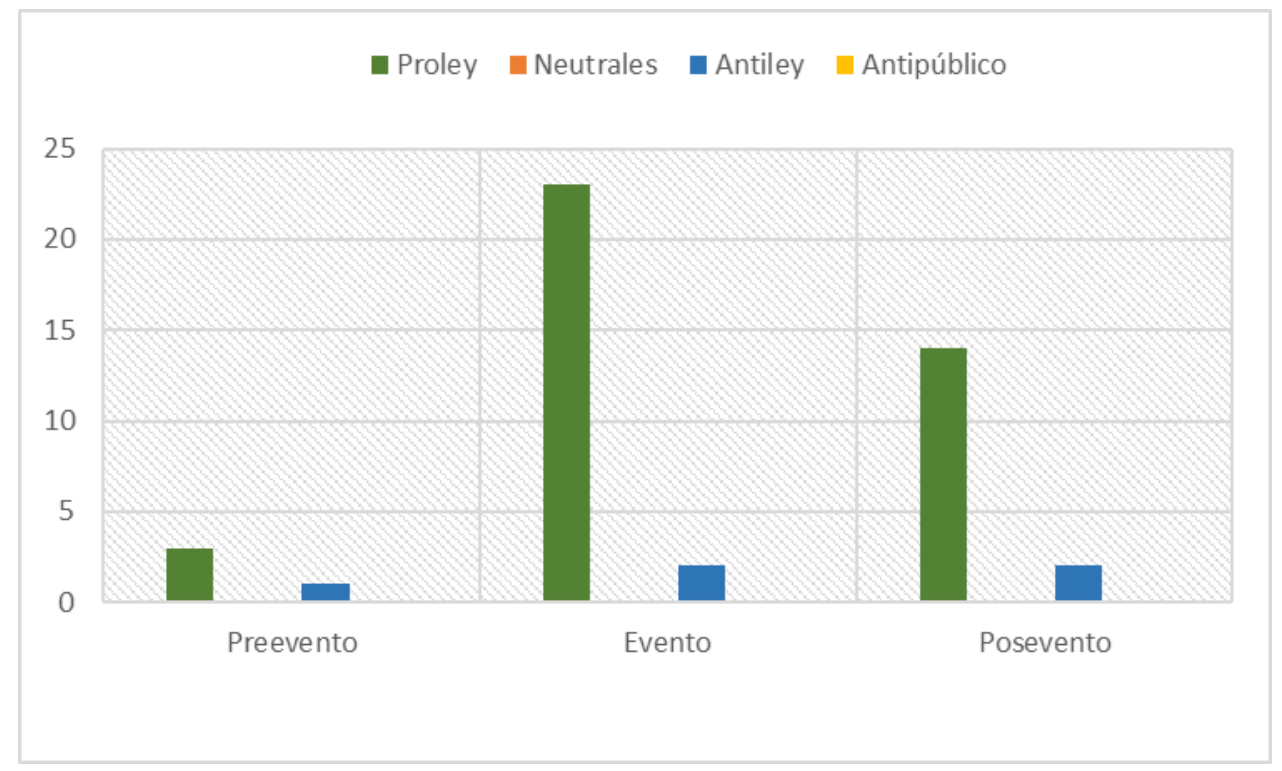

Fuente: Elaboración propia.

La mayoría de las veces, esas publicaciones risibles en los hashtags operaron como "misiles de sentido" enviados desde el campo enemigo. Así, por ejemplo, se hallaron tuits burlándose del presidente y la vicepresidenta en hashtags propuestos por el 
oficialismo como \#TodosConAlberto y \#AsambleaLegislativa2020, y tuits ridiculizando los principios religiosos contra el aborto en \#ArgentinaEsCeleste y \#ArgentinaEsProvida.

\subsection{LOS INTERPRETANTES REIDEROS}

Como planteamos arriba, los memes y tuits risibles son interpretantes que enmarcan en lo reidero el evento transmitido por la televisión. En ese enmarque, lo enunciativo cumple un papel fundamental porque propondrá una u otra lectura, incitará una u otra fuente de placer risible y señalará de qué o de quién reírse y con qué colectivo se identifica uno al hacerlo. Como ya advertimos, un mismo meme será cómico u humorístico según quién lo enuncie. Buscando regularidades en esa compleja producción, identificamos en ambos eventos cuatro clases de lo risible del live tweeting con sus particulares modos enunciativos: la sátira política, la burla, la situación cómica y el humor del colectivo.

\subsubsection{La sátira política}

El género de la sátira política lo encontramos en su estilo moderno: el enunciador se alía al enunciatario con el fin de ridiculizar y criticar la moral y las prácticas de los políticos, los ciudadanos y las instituciones. En el discurso de Fernández, apareció en el antioficialismo y no en el oficialismo. Predominó la figuración del presidente como un asesino de bebés por promover la legalización del aborto, un títere manipulado por la vicepresidenta, un mentiroso por no haber mejorado aún la situación económica, como había prometido en la campaña electoral, y por sostener que su gobierno era de científicos cuando en realidad existen otros actores de peso como sus cuadros políticos y los gremialistas aliados. En esta línea risible, se formó un hashtag con el nombre \#Alverso ${ }^{13}$. Los otros blancos privilegiados fueron la vicepresidenta, que se la satirizó por manipular al presidente, y los gremialistas, que aparecieron en el palco del Congreso representándolos como ancianos mafiosos (imagen.1).

En el debate del senado, la sátira se presentó en un mayor porcentaje en los antiley y antipúblico y, en menor medida, en los proley y neutrales. Los antiley, por un lado, acusaron a senadores de haber vendido su voto. Por otro lado, desenmascararon al

\footnotetext{
${ }^{13}$ En Argentina "verso" significa mentira, engaño.
} 
colectivo proaborto sosteniendo que el verdadero objetivo del aborto era disminuir el número de pobres y no defender los derechos de las mujeres.

Los proley también desenmascararon al colectivo opositor denunciando su doble moral, decir defender la vida de los niños, pero, una vez que nacen y viven en la pobreza, despreciarlos y pedir pena de muerte cuando delinquen. A su vez, su sátira también atacó a la iglesia figurándolos como violadores de menores y a los políticos y periodistas por defender abortos clandestinos sin importarles las muertes de las mujeres (imagen 2).

Los neutrales, acusaron a los proley y antiley por aumentar el contagio del coronavirus al manifestarse frente al Congreso. Los antipúblico incriminaron a los políticos proley de usar sus impuestos para pagar abortos de los pobres, quienes los figuraron como irresponsables que no miden las consecuencias de sus impulsos sexuales.

Imagen 1. Sátira a gremialistas

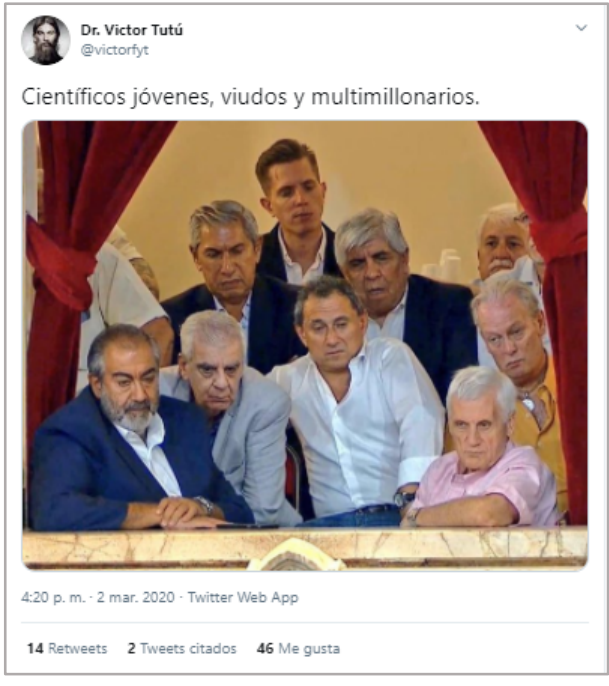

Fuente: Dr. Victor Tutú
Imagen 2. Sátira a periodistas y políticos

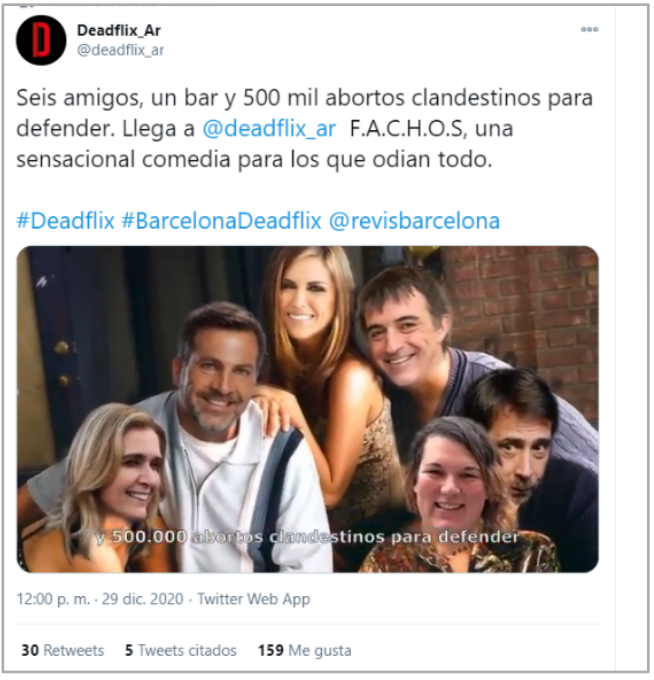

Fuente: Deadflix_Ar

\subsubsection{La burla}

La burla es un género de gran extensión en las redes y puede adoptar estilos de lo más crueles debido a la baja regulación institucional. Como categoría analítica la diferenciamos de la sátira porque las incongruencias que promueven el efecto risible no se despliegan en las desviaciones de los ideales morales y de conducta que se esperan de los políticos e instituciones sino de los verosímiles asociados a las formas de la 
naturaleza (formas del cuerpo, de los movimientos, etc.) y la vida social (verosímiles del vestir, comportarse, hablar, etc.). A diferencia de la sátira, la burla se desarrolló tanto en el oficialismo como en el antioficialismo. El primero tuvo una burla triunfante con blanco en el expresidente Macri y sus seguidores. Los ridiculizó sufriendo por ver a sus contrincantes en el poder, a Macri se lo comparó con un burro analfabeto y a sus seguidores con gorilas continuando la tradición de identificar a esos animales con el antiperonismo.

La burla del antioficialismo recayó sobre las formas del cuerpo, la vestimenta, caracteres y capacidades intelectuales. El blanco central fue la vicepresidenta que se la acusó de tener mal carácter, de comportarse de manera inadecuada y se la igualó a los papagayos y payasos por vestir colorido (imagen 3). Al presidente se lo trató de idiota al igual que sus votantes a quienes también se los ridiculizó por pobres y se los representó como sucios y crédulos.

En el debate sobre el aborto, la burla predominó en los proley. Ridiculizaron a los senadores y al colectivo antiley por ser fundamentalistas religiosos y sostener argumentos tan antiguos que los representaron habitando el Medioevo o siendo dinosaurios (Imagen 4). La burla también recayó en individualidades: Amalia Granata, senadora popular por su pasado mediático, el muñeco de un feto gigante hecho por los manifestantes antiley y "la Petisa", la madre antiley que nombrábamos antes, conocida por un móvil televisivo. Hacia el fin de debate y cuando la ley se aprobó, se multiplicaron burlas celebratorias mofándose de los antiley por haber perdido la votación.

Los otros enunciadores en los que predominó la burla fueron los neutrales. Ellos atacaron a los colectivos en disputa figurándolos como odiadores incapaces de dialogar; al debate en sí por considerarlo de poca importancia frente a otros problemas del país, y a la propia transmisión televisiva por ser un espectáculo aburrido. 
Imagen 3. Burla a Cristina Fernández

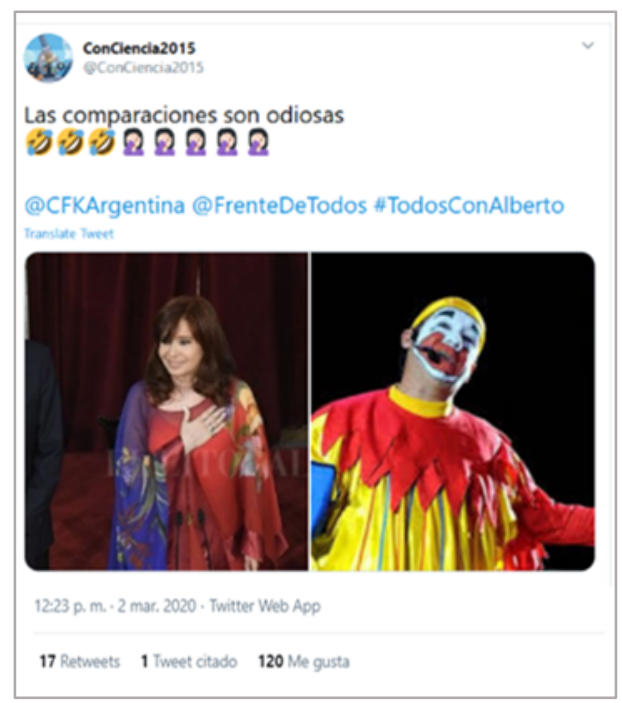

Fuente: ConCiencia2015
Imagen 4. Burla al senador José Mayans, opositor a la aprobación de la ley

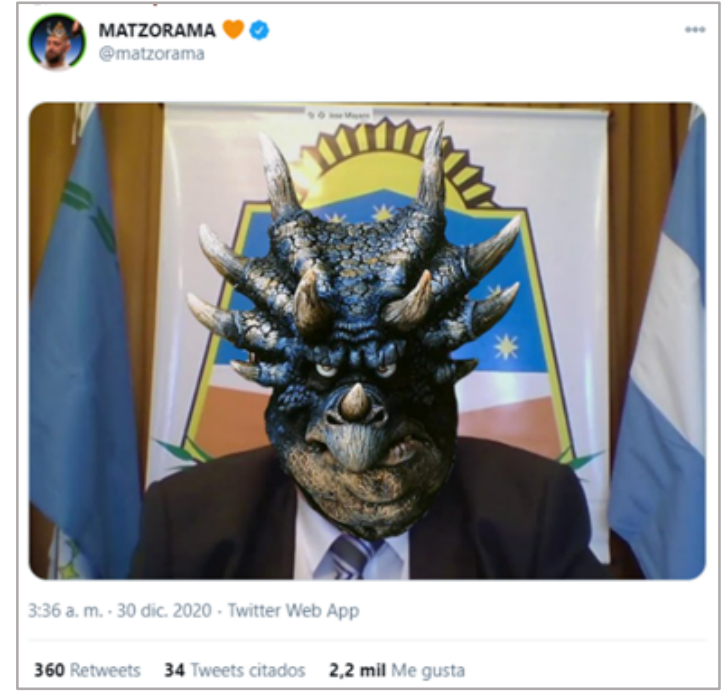

Fuente: Matzorama

\subsubsection{Situación cómica}

Como en las tipologías anteriores, en la situación cómica también hay una alianza entre el enunciador y enunciatario en el rebajamiento del blanco. No obstante, su razón no se fundamenta en una propiedad del referente, como ocurre en la burla, ni existe una crítica sobre su conducta o moral, como en la sátira. Lo que hace risible al referente es la particular situación en la que se encuentra. Vale aclarar que esa situación no se halla en el evento transmitido en sí sino en la discursividad del tuit, aunque él es su condición de producción. Por ello, es posible que no haya producción risible de situaciones cómicas, como ocurrió con el evento del debate del Senado.

Sí, en cambio, hubo situaciones cómicas en el discurso del presidente Fernández. La situación más referenciada fue que al gobernador de la provincia de Buenos Aires, Kicillof, lo sentaron junto al expresidente Menem. Los tuits procesaron cómicamente la situación por dos vías fundamentalmente: por la contraposición de posturas políticas (Kicillof se identifica con la izquierda del peronismo mientras que Menem con el peronismo neoliberal) y de temporalidades (Kicillof, la juventud y el presente; Menem, la vejez y el pasado) (imagen 5). La segunda situación cómica más producida fue la que se basó en un supuesto regaño de la vicepresidenta al presidente. 
Una cuestión que diferencia a las situaciones cómicas de la sátira política y la burla es que el mismo meme suele ser compartido por oficialistas y antioficialistas. Una hipótesis que puede esgrimirse es que, al no estar lo reidero fundamentado en lo político, se eluden las censuras ligadas a la identidad partidaria que inhibirían el placer de la risa. Eso posibilitaría una mayor propagación en la red en comparación a la sátira política y la burla.

Imagen 5. Situación cómica Menem- Kicillof

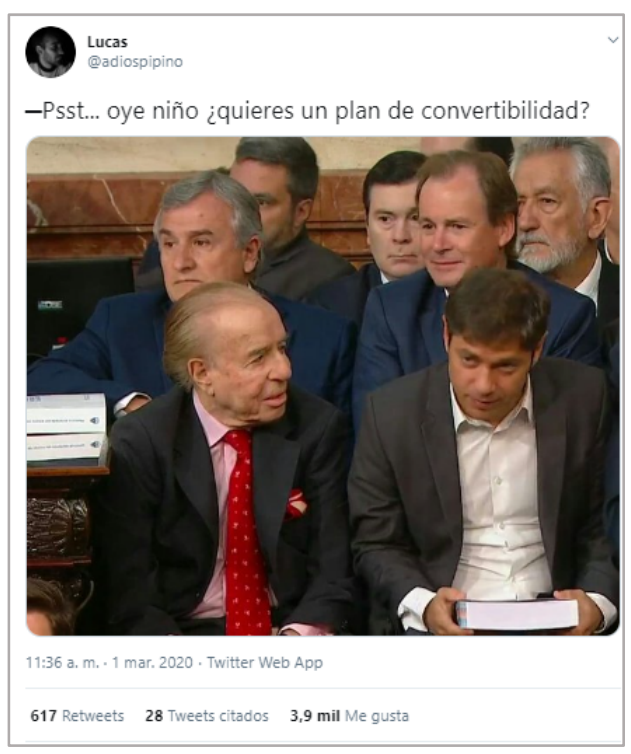

Fuente: Lucas

\subsubsection{Humor del colectivo}

El humor del colectivo se distingue de las anteriores categorías porque se emplaza en el régimen del humor antes que del cómico y, si éste aparece, se despliega con mesura y empatía. El humor, a diferencia de lo cómico, se desarrolla en una operación reflexiva en la que el enunciador y enunciatario se identifican con el objeto de la burla. ${ }^{14}$ En el discurso de Fernández, encontramos dos referentes privilegiados: el presidente y el colectivo oficialista. Sobre el presidente proliferaron memes riéndose de él por su parecido a Geppetto y Harry Potter (imagen 6) ${ }^{15}$. En ambos casos, los enunciadores se disculpaban al hacer la broma o daban indicios de que no tenían ánimo de ofender sino de homenajear. En el humor del colectivo, lo cómico no es un ataque para rebajar al

\footnotetext{
14 Seguimos aquí los planteos de Steimberg (2001) que observó que el humor mediático existe a condición de que el enunciador asuma la identificación con un segmento estilístico (etario, regional, partidario, etc.). Ello posibilitaría que el receptor, al reconocerse en ese segmento, transite el rebajamiento y distanciamiento que habilitaría lo risible humorístico.

${ }^{15}$ En ambos casos la comparación es con los personajes de las transposiciones cinematográficas llevadas a cabo por Disney (Pinocho 1940) y Warnes Bros (la serie de Harry Potter, 2001, 2002, 2004, 2005, 2007, 2009, 2010 y 2011).
} 
referente sino una muestra de cariño y de afirmación del vínculo, como ocurre con las bromas entre amigos. El segundo referente adoptó justamente esa forma. Proliferaron los memes hechos por simpatizantes del gobierno que se reían de sí mismos por la alegría que les provocaba asistir al discurso del presidente que votaron.

En el debate sobre el aborto, solo encontramos humor del colectivo en los proley y, especialmente, en dos momentos: en el anterior al debate y en su finalización. En el momento anterior, el colectivo se burló de sí mismo por los nervios y la ansiedad que les provocaba el evento (imagen 7). Y, en el posterior, se celebró ridiculizándose con exageradas manifestaciones de alegría que, en muchas ocasiones, implicaban una apropiación absurda de los argumentos usados contra la ley. Así, por ejemplo, aludiendo a la premisa de que la ley conllevaría la instalación del hábito de abortar, se publicaron memes en que Homero Simpson, en lugar de invitar a sus compañeros de bar una cerveza, invitaba un aborto. 0 , haciendo referencia a que detrás de la ley había un negocio de venta de fetos a la industria alimenticia, se publicaron memes en los que feministas festejaban cocinando bebés.

Imagen 6. Lo cómico en el humor del colectivo y su reconocimiento

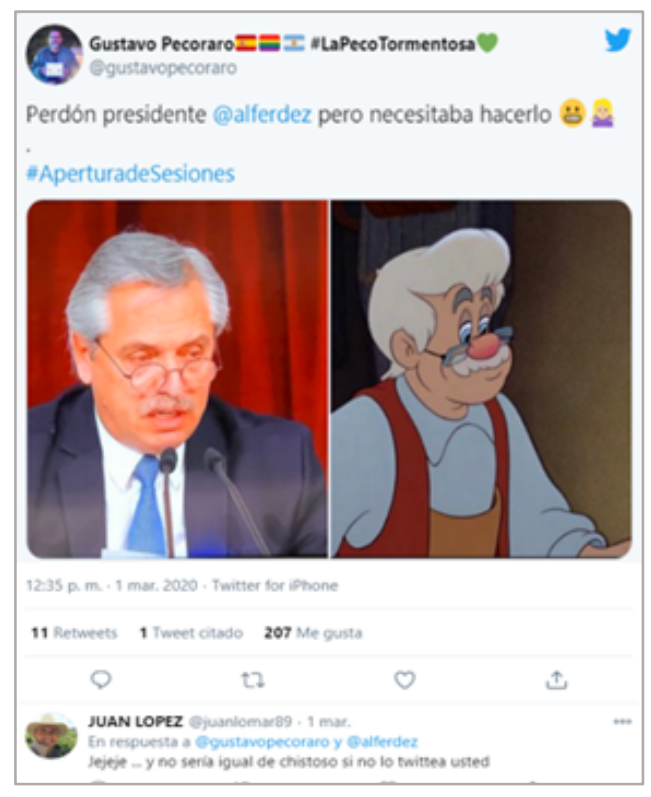

Fuente: Gustavo Pecoraro
Imagen 7. Humor del colectivo proley

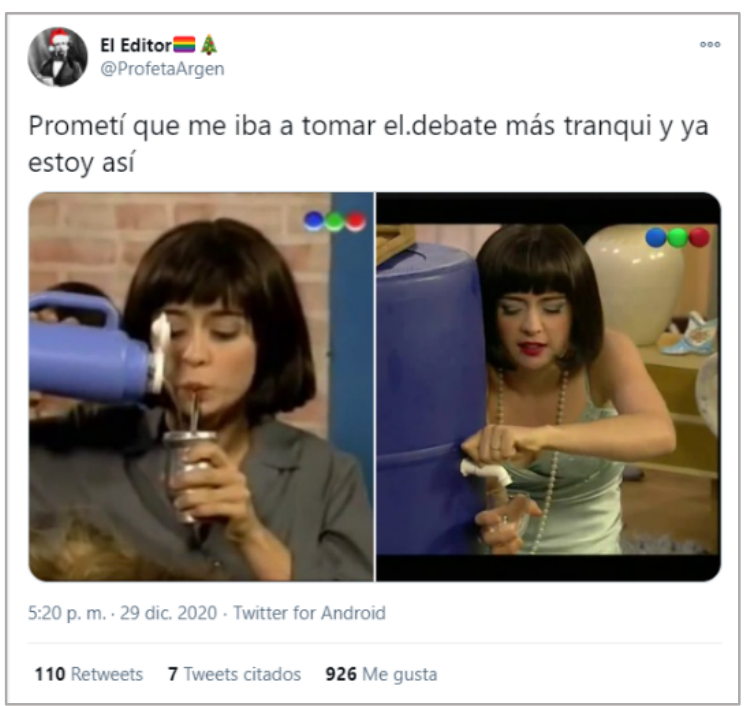

Fuente: El editor

El humor del colectivo es la categoría donde mejor se aprecia la importancia de prestar atención a lo enunciativo para clasificar lo reidero, porque los mismos chistes pasan de 
ser humorísticos a ofensivamente cómicos si los enuncia un oficialista o antioficilista, un proley o un antiley. $\mathrm{Y}$ esto no es únicamente una cuestión analítica, sino que está íntimamente ligada a los placeres que justifican su vida social. En reconocimiento, los simpatizantes del gobierno de Fernández o los que apoyan la ley de interrupción del embarazo aceptan y comparten las ocurrencias descriptas porque registran que provienen de integrantes del propio colectivo. Por esta naturaleza, el humor del colectivo es la clase risible más propensa a presentar mayor circulación de sentido porque, en su propagación, puede perder el anclaje político.

\section{LA APROPIACIÓN DE LAS INSTITUCIONES INFORMATIVAS}

Al poco tiempo de aparecer el live tweeting, los medios de comunicación masiva y los portales de noticias destinaron un espacio para los memes que se producen en torno a un evento. Los medios lo presentan como "lo que dijo la gente" sin asumir su autoría en la selección. Como enseguida veremos, cuando analizamos su curaduría puede apreciarse cómo ella editorializa el acontecimiento. Para describirla utilizamos las clases de lo risible, antes definidas, dividiendo la sátira política y la burla en "en contra" y "a favor" de Fernández y la aprobación de la ley.

Sobre el discurso de Fernández, el gráfico de abajo (gráfico 7) exhibe que los portales de noticias se apropiaron de los memes más que los portales de medios masivos. En la mayoría hubo una ausencia de sátiras a favor del gobierno como también la hubo en los hashtags y cuentas de Twitter analizados. Los portales que figuraron una evaluación más crítica del discurso fueron Infobae, La 100 radio, Cholionline y Nuevo diario web. En los tres primeros, la sátira aparece en mayor proporción acompañada por la burla antioficialista y el humor del colectivo. Éste último, al enmarcarse en un medio distanciado del gobierno o directamente opuesto a él, atenúa su carácter humorístico y fortalece su comicidad. El tuit que antes era una humorada entre militantes pierde el anclaje enunciativo que lo protege de interpretarse como una mera burla.

La Verdad noticias y Los Andes también seleccionaron más sátiras y burlas contra el gobierno, no obstante, los dos últimos dieron espacio para la burla a los contrincantes del gobierno y Los Andes introdujo la sátira a favor del oficialismo. En una posición 
contraria encontramos a El Destape, único portal que no expuso sátira contra el gobierno y se centró en inocuas situaciones cómicas y humor militante que, al ser un medio expresamente kirchnerista, mantuvo su carácter humorístico.

Filo news y La 97.1 Radio, aunque presentaron sátira contra el gobierno, hubo un número mayor de burlas a sus oponentes. Y, finalmente, MDZ aparece como el más equilibrado, aunque, en su selección, la sátira y la burla rebajaron fuertemente al presidente figurándolo como títere de la vicepresidenta y es el único portal que cita un hashtag que lo insulta: \#AlbertoPelotudo. A pesar de esta excepción, en el resto de los portales prevaleció la sátira y la burla regulada por la institución, es decir, no apareció la ridiculización desalmada ni obscena. Tal vez esa fue una de las razones de que las burlas a la vicepresidenta no ascendieran, a pesar de abundar en las redes.

Sintetizando, entonces, podemos decir que, salvo El Destape, Filo news y La 91.7 Radio, la mayoría de los portales se sirvió de lo risible para construir una opinión pública crítica hacia el presidente y sus aliados mediante la sátira política, la burla y el humor del colectivo.

Gráfico 7. Las clases del humor político del live tweeting apropiadas por los portales de noticias y de medios masivos en el discurso de Fernández

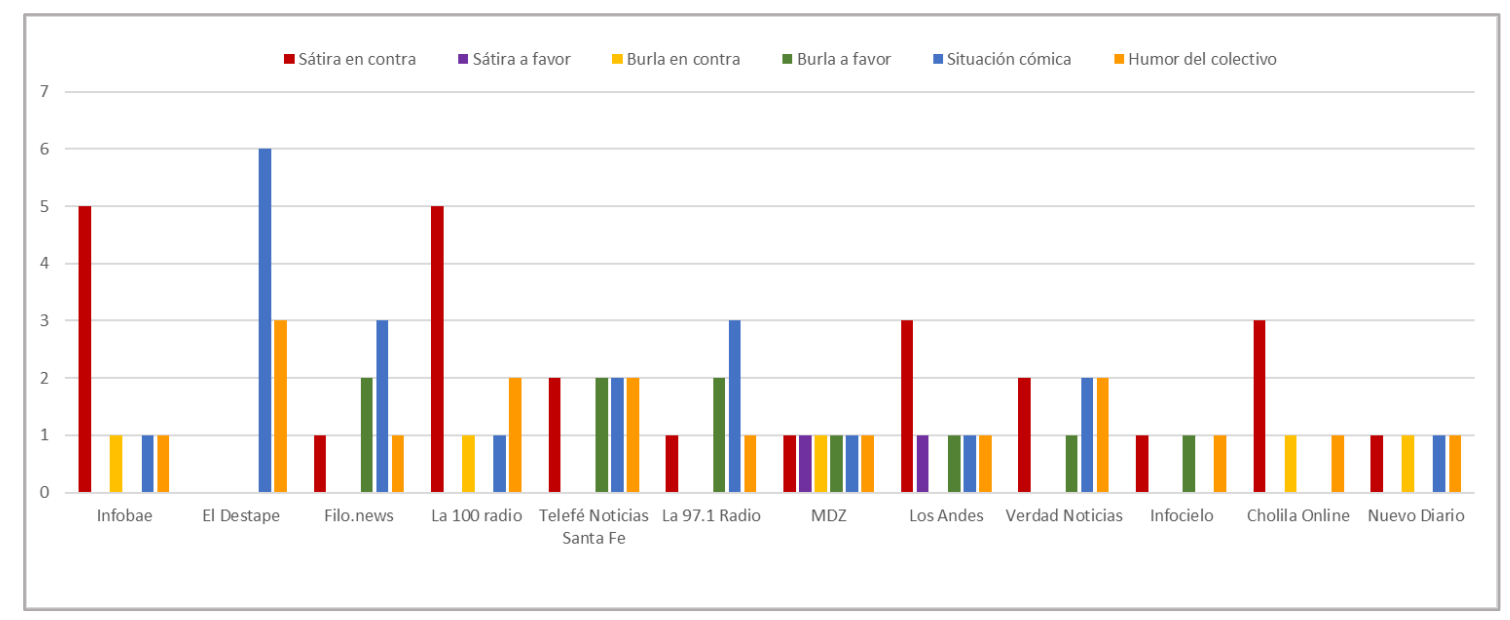

Fuente: Elaboración propia.

Los portales de noticias y medios masivos actuaron diferente con respecto al debate del senado (gráfico 8). Fue un número menor el que se apropió de los memes y su curaduría coincidió en apoyar la aprobación de la ley. Ese apoyo se dio de dos maneras. La primera, recogiendo las burlas que se hicieron a representantes de los opositores a la aprobación 
de la ley. TN recogió las burlas contra la senadora Amalia Granata, La Nación contra el senador Dalmacio Mera y El Destape y Uno Santa Fe contra el hijo de la Petisa. La segunda manera fue tomar los festejos de los proley en Twitter. Infocielo tomó la sátira política y la burla a favor de la ley y el humor del colectivo celebrando su aprobación.

Gráfico 8. Las clases del humor político del live tweeting apropiadas por los portales de noticias y de medios masivos en el debate del Senado

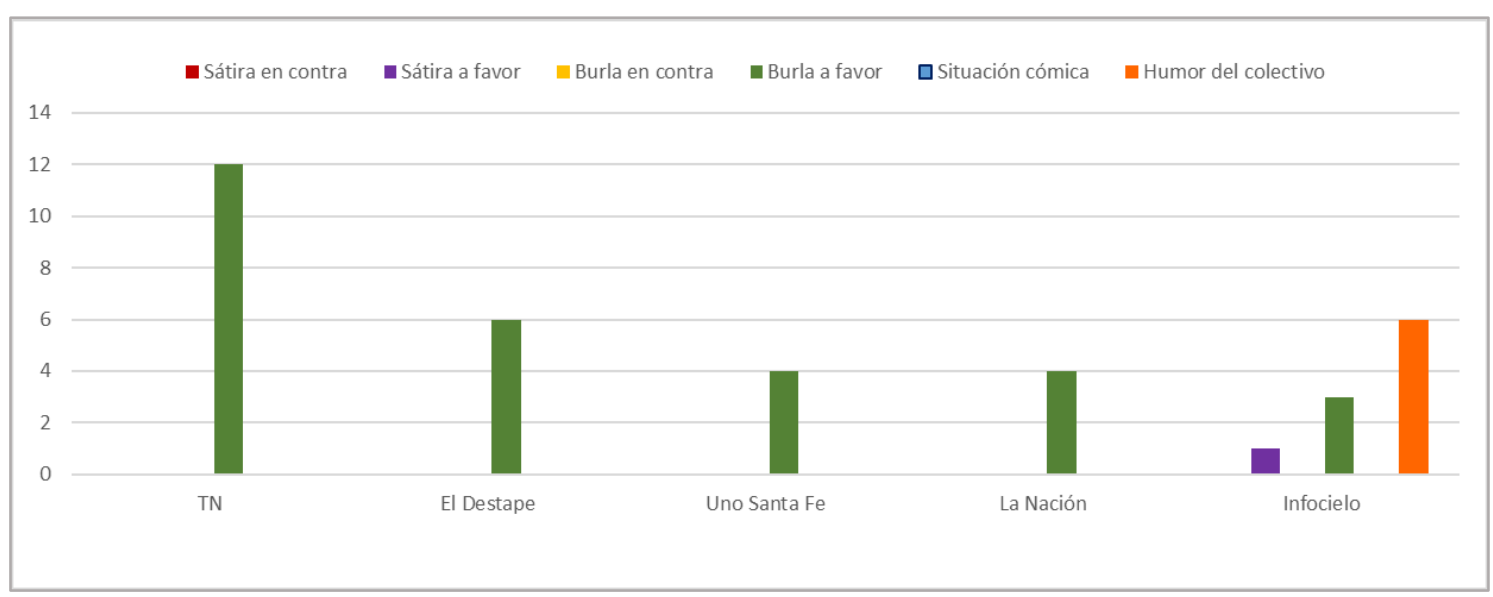

Fuente: Elaboración propia.

\section{EL HUMOR POLÍTICO DEL LIVE TWEETING, UN NUEVO INTERPRETANTE EN LA CONSTRUCCIÓN DE LOS ACONTECIMIENTOS}

La comparación de lo risible del discurso de Fernández y el debate sobre el aborto nos permitió advertir singularidades y regularidades que significan un aporte al conocimiento de cómo opera el humor político del live tweeting en la construcción de acontecimientos. Entre las singularidades advertimos que los colectivos en disputa no siempre generan lo reidero y, cuando lo hacen, no desarrollan la misma estrategia. Si en el discurso de Fernández, los oponentes produjeron cantidades similares de tuits graciosos, en el debate sobre el aborto, fue muy desigual. La generación reidera de los opositores a la ley fue mínima con relación a la de los que la apoyaban. Esa diferencia da cuenta de posibilidades y restricciones en la producción de sentido. El colectivo que practica lo reidero extiende lo decible y lo visible del tema en cuestión porque accede a polifonías, síntesis y agresiones vedadas para los que limitan su discursividad a lo serio.

A su vez, también observamos que la distribución del humor político no fue equivalente. Mientras que en el discurso de Fernández fue más regular, en el debate sobre el aborto 
se concentró durante transcurso del evento. Tampoco fue equivalente la manera en que los portales de noticias y de medios masivos se apropiaron de los memes. Si sobre el discurso de Fernández hubo variedad en las posiciones políticas, sobre el debate del Senado predominó la posición proley que se manifestó en una curaduría que tomó las burlas hacia los representantes del colectivo opositor.

Ahora bien, más allá de estas particularidades, nuestro estudio halló varias recurrencias que nos permiten hablar de ciertas gramáticas establecidas en el humor político del live tweeting. Para comenzar, los datos cuantitativos confirmaron observaciones de estudios anteriores: 1 ) sus tuits tienen una tasa de retuiteo mayor que los serios; 2 ) su producción se da antes, durante y después del evento; 3) por su capacidad de propagación, sostiene temas y figuraciones en el tiempo; 4) en los intercambios que provoca se introduce lo serio, por lo que amplía y fomenta el debate político entre los internautas.

Los datos también nos permitieron ver que el destinatario privilegiado del humor político del live tweeting es el propio colectivo. No obstante, su alto grado de propagación y su apropiación por los medios masivos y digitales hacen que alcancen importantes escalas de distribución y se fomente su circulación.

En relación con el análisis cualitativo, pudimos probar lo significativo que es prestar atención al nivel enunciativo para ordenar el corpus de análisis y discriminar cómo opera lo rediero. Dos tuits podrán tener el mismo tema, pero según cómo establecen los vínculos entre el enunciador, el enunciatario y el objeto de la burla, convocarán el placer reidero de modos diferentes y esos modos hacen a la conformación de colectivos y condicionan propagaciones y circulaciones. Atendiendo a esto, pudimos distinguir cuatro clases discursivas: sátira política, burla, situación cómica y humor del colectivo. Cada una de ellas propone el contacto con diferentes fuentes del placer risible y vínculos particulares con los eventos construidos y los actores que se ponen en juego en esa construcción.

Tener en cuenta estas clases discursivas también nos sirvió para describir las apropiaciones que hicieron los medios. Como pudimos observar, los portales de noticias y medios masivos cumplen un rol fundamental en el ascenso de lo reidero. En su 
curaduría, esas instituciones informativas, opinan sobre el evento jugando a que no lo hacen, postulando que se trata de ocurrencias chistosas de los internautas. Así, contactan a sus visitantes con figuraciones que solo se dan en la libertad de lo risible no regulado institucionalmente. Por esta razón, y las ya presentadas, podemos afirmar que el humor político del live tweeting es un nuevo actor para tener en cuenta si se quiere comprender cómo se construyen los acontecimientos en directo en las sociedades contemporáneas.

\section{AGRADECIMIENTOS}

El estudio que originó este artículo fue financiado por la Universidad de Buenos Aires, Argentina, y se realizó en el marco del proyecto de investigación La mediatización en el entretejido de los vínculos sociales. Cambios en la circulación del sentido a partir de la nueva mediatización de individuos, colectivos e instituciones en la sociedad contemporánea, dirigido por el Dr. Mario Carlón.

\section{REFERENCIAS BIBLIOGRÁFICAS}

Bateson, G. (1985), Pasos hacia una ecología de la mente. Buenos Aires: Carlos Lohle.

Carlón, M. (2020). Circulación del sentido y construcción de colectivos en una sociedad hipermediatizada. San Luis: Universidad Nacional de San Luis. Recuperado de http://www.neu.unsl.edu.ar/wp-content/uploads/2020/08/Circulacio\%CC\%81n-delsentido.pdf

Carlón, M. (2015). Registrar, subir, compartir. Prácticas fotográficas en la era Contemporánea. En Actas V Simposio Internacional de Estética: estética, medios y subjetividades (pp. 134-156). Santiago de Chile: Pontificia Universidad Católica.

Davis, J., Love, T., Avis, J., y Killen, G. (2018). Seriously funny: The political work of humor on social media. New media \& Society, 20,45-57. Recuperado de https://journals.sagepub.com/doi/abs/10.1177/1461444818762602?journalCode=nmsa

Driscoll, K., Leavitt, A., Kristen, L., Riscoll, K., Leavitt, A., Kristen, L.G., François, B. y Aalot, M. (2013). Big Bird, Binders, and Bayonets: humor and livetweeting during the 2012 U.S. Presidential debates. New media \& Society, 11, 67-83. Recuperado de https://spir.aoir.org/index.php/spir/article/download/736/326 
Fraticelli, D. (2021). Enunciación y humor en las redes (o cómo estudiar memes sin perder el chiste). La trama de la comunicación, 25(2), 115-129. Recuperado de https://latrama.fcpolit.unr.edu.ar/index.php/trama/article/view/779

Fraticelli, D. (2019). El ocaso triunfal de los programas cómicos. Buenos Aires: Teseo. Recuperado de https://www.editorialteseo.com/archivos/17065/el-ocaso-triunfal-delos-programas-comicos/

Fraticelli, D. (2018). El ascenso de la burla en las sociedades contemporáneas: nuevas circulaciones del humor mediático. Rizoma, 6(1), 51-63. Recuperado de https://online.unisc.br/seer/index.php/rizoma/article/view/12614

Fraticelli, D., Gómez Blanco, C., Saldaña, B. y Taraborelli, D. (2020). El humor hipermediático en la construcción del acontecimiento. En Anais de Artigos. IV Seminário Internacional de Pesquisas em Midiatização e Processos Sociais, 1(4), 234-356.

Freeom, D. y Karpf, D. (2014). Of big birds and bayonets: hybrid Twitter interactivity in the 2012 Presidential debates. Information, Communication \& Society, 18(4), 2014. https://doi.org/10.1080/1369118X.2014.952659

Goffman, E. (2006), Frame Analysis. Los marcos de la experiencia. Buenos Aires: Centro de Investigaciones Sociológicas.

Highfield, T. (2015). News via Voldemort: parody accounts in topical discussions on Twitter. New, Media \& Society, 18(9), 2028-2045.

https://doi.org/10.1177/1461444815576703

Jenkins, H., Ford S. y Green, J. (2015). Cultura transmedia. La creación de contenido y valor en una cultura en red. Barcelona: Gedisa.

Maradei, A. (2017). Humor e violência no Tuíter durante os protestos pelo impeachment de Dilma Rousseff. Estudos em Comunicação, 26(2), 137-148. Recuperado de http://ojs.labcom-ifp.ubi.pt/index.php/ec/article/view/461 Peirce, C. S. (1974). La Ciencia de la semiótica. Buenos Aires: Nueva Visión. 
Scolari, C. A. (2013). Narrativas Transmedia. Cuando todos los medios cuentan. Deusto: Deusto Ed.

Steimberg, O. (2001). Sobre algunos temas y problemas del análisis del humor gráfico, Signo y seña, 7, 56-72.

Traversa, O. (2009). Notas acerca de lo reidero en las tapas de revistas. Figuraciones. Teoría y crítica de artes, 5, 49-63.

Verón, E. (2013). La semiosis social II. Ideas, momentos, interpretantes. Buenos Aires: Gedisa.

Verón, E. (1987a). Construir el acontecimiento. Buenos Aires: Gedisa.

Verón, E. (1987b). La semiosis social. Buenos Aires: Gedisa.

Wells, C., Van Thomme y J.V., Maurer, P. (2013). Coproduction or cooptation? Realtime spin and social media response during the 2012 French and US presidential debates. French Politics, 14(2), 206-233. Recuperado de https://cutt.ly/HOWs7uc 